\title{
Beyond the Disease - History of the House for Patients with Chagas Disease and Heart Failure of Pernambuco (Casa do Portador de Doença de Chagas e Insuficiência Cardíaca de Pernambuco)/PROCAPE-UPE/Brazil
}

\author{
Silvia Marinho Martins, ${ }^{1}{ }^{\circledR 0}$ Cassandra Barros Correia de Moura, ${ }^{1}{ }^{\circledR}$ Maria da Glória Aureliano de Melo Cavalcanti, ${ }^{\circledR 0}$ \\ Cristina de Fátima Velloso Carrazzone, ${ }^{1 \text { (으 }}$ Carolina de Araújo Medeiros, ${ }^{10}$ Wilson Oliveira Junior ${ }^{10}$ \\ Ambulatório de Doença de Chagas e Insuficiência Cardíaca do Pronto Socorro Cardiológico de Pernambuco Prof. LuizTavares - PROCAPE- \\ Universidade de Pernambuco - UPE, 1 Recife, PE - Brazil
}

"Utopia is on the horizon. I move two steps closer; it moves two steps further away. I walk ten steps and the horizon runs ten steps further away. As much as I may walk, I will never reach it. So what is the point of utopia?

The point is this: to keep walking".

Fernando Birri.

\section{Where it all began}

The history of the Chagas Disease and Heart Failure Outpatient Clinic of the Prof. Luiz Tavares Cardiology Emergency Unit of Pernambuco, at Universidade de Pernambuco (UPE), began in August 1987 at Hospital Universitário Oswaldo Cruz (HUOC). When it was created, in 1884, this hospital worked mainly providing care for patients with infectious and parasitic diseases. Since that time, the hospital worked with diseases that later became known as unassisted (nowadays named and classified as neglected diseases by the World Health Organization, WHO) and became a breeding ground for the inauguration of the Chagas Disease Outpatient Clinic.

In 1964, HUOC became a teaching hospital and started receiving medical students from Faculdade de Ciências Médicas de Pernambuco. At this moment, the hospital became the first referral center for clinical and surgical cardiology in the state, being the main and only public emergency unit exclusively dedicated to this specialty. The emergency demand was massive and various sectored wards were established for treating and caring for patients with heart disease. Among them, the myocardiopathies and heart failure ward, in the late 1970s, was coordinated by Professor Wilson de Oliveira Jr. In general, patients arrived at the cardiology emergency unit with decompensated heart failure, being cared for and referred to the myocardiopathy ward (Figure 1). Once compensated, these patients were discharged without systematic outpatient care, which resulted in various new hospitalizations. Many of these patients had chagasic heart failure.

\section{Keywords}

Chagas Disease; Heart Failure; Outpatient.

Mailing Address: Silvia Marinho Martins •

Casa de Chagas - PROCAPE -UPE - R. Álvares de Azevedo, 220.

Postal Code 50100-040, Santo Amaro, Recife, PE - Brazil

E-mail:s.m.martins@uol.com.br

Manuscript received April 28, 2021, revised manuscript June 02, 2021, accepted June 08, 2021

DOI: https://doi.org/10.36660/abchf.20210003
This finding led physicians Wilson Oliveira Jr. and Cassandra Barros Correia to propose to the hospital board of directors the creation of an outpatient clinic specifically for patients with Chagas disease who left the myocardiopathy ward, whose social implications were and continue to be very specific. The idea was embraced with enthusiasm by the HUOC director at the time, who was also a cardiologist, Ricardo Paiva (Figure 2). The proposal aimed to positively impact the hospital's emergency and hospitalization demands. Patients with controlled disease would not need to seek this more complex care. At that moment, the ideal that would guide the organization of the Unified Health System (SUS), which was created in 1988, was already taking shape at HUOC, with the hierarchization of health services.

Therefore, with a small room, two physicians and one nurse (Valdinete Paiva), the HUOC's Chagas Disease Outpatient Clinic began operating, defending the motto "Humanizing for caring." Due to the restricted space and reduced staff, the assistance provided by the clinic was limited to the biomedical sphere. In face of the complexity of Chagas disease, with its social, economic, and psychological implications, the team felt the need to transcend the strictly biomedical approach into a more complete care, meaning a whole health care performed by a multidisciplinary team, which to the current day has been scientifically proven as the best option when caring for chronic patients. ${ }^{1}$ In this perspective, the need to evaluate the patient as a whole was already clear, with the challenge of adopting the biopsychosocial model of care: It proposes a view of much more than a sick organ but also the person, his or her history, family, and socioeconomic context. For this, a group of professionals that helped increase the perception of various aspects of the reality of an individual was needed. ${ }^{2}$

At the same time, the clinic team had always sought to empower patients, providing them with more conscience of the social issues involving the disease and of the need to articulate and associate for together having more strength and amplifying their voices for fighting for their causes and for supporting each other, especially considering the neglected characteristic of this disease. The understanding was that the patient had to play an active role and not only be on the receiving end of the information flow. This is how the Pernambuco Association of Chagas Disease Patients was born, with the motto "A commitment with life"; it was the world's first association of people with Chagas disease. 


\section{Special Article}

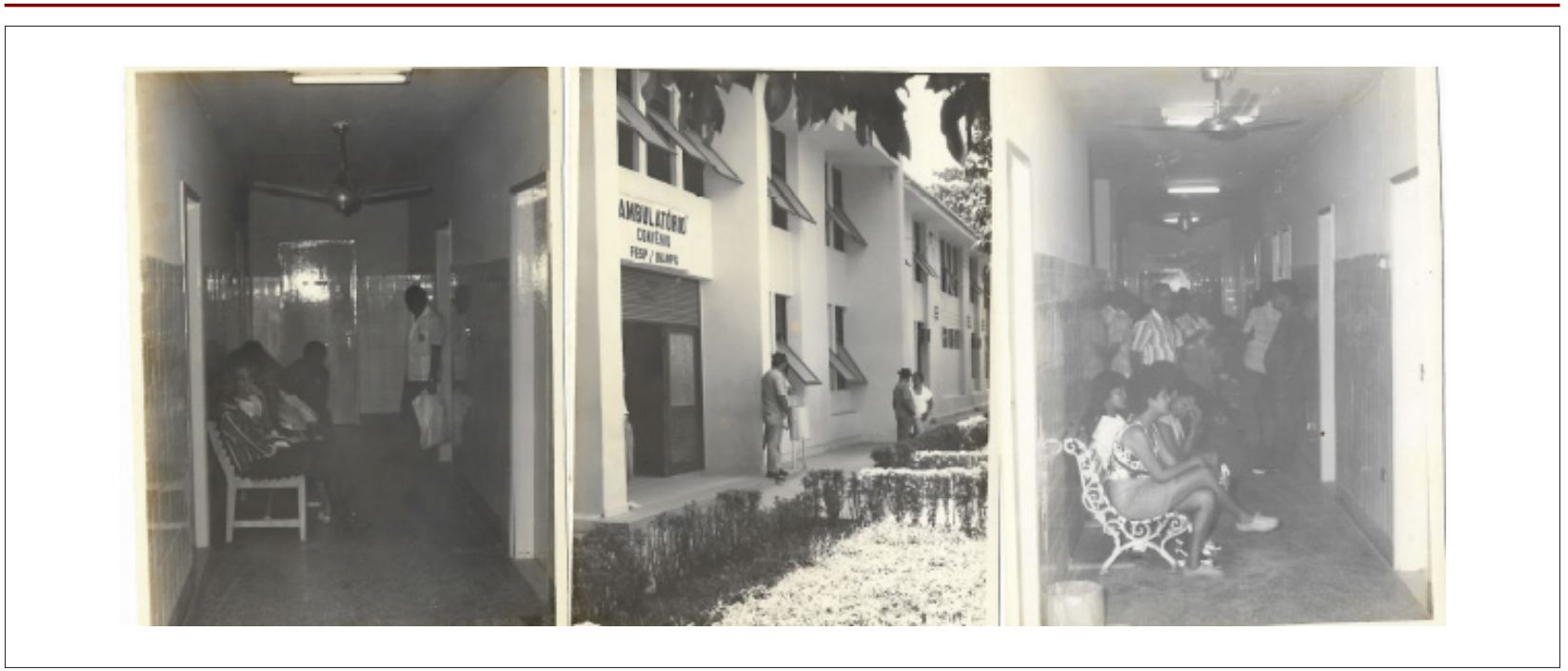

Figure 1 - Operating outpatient clinic at HUOC.

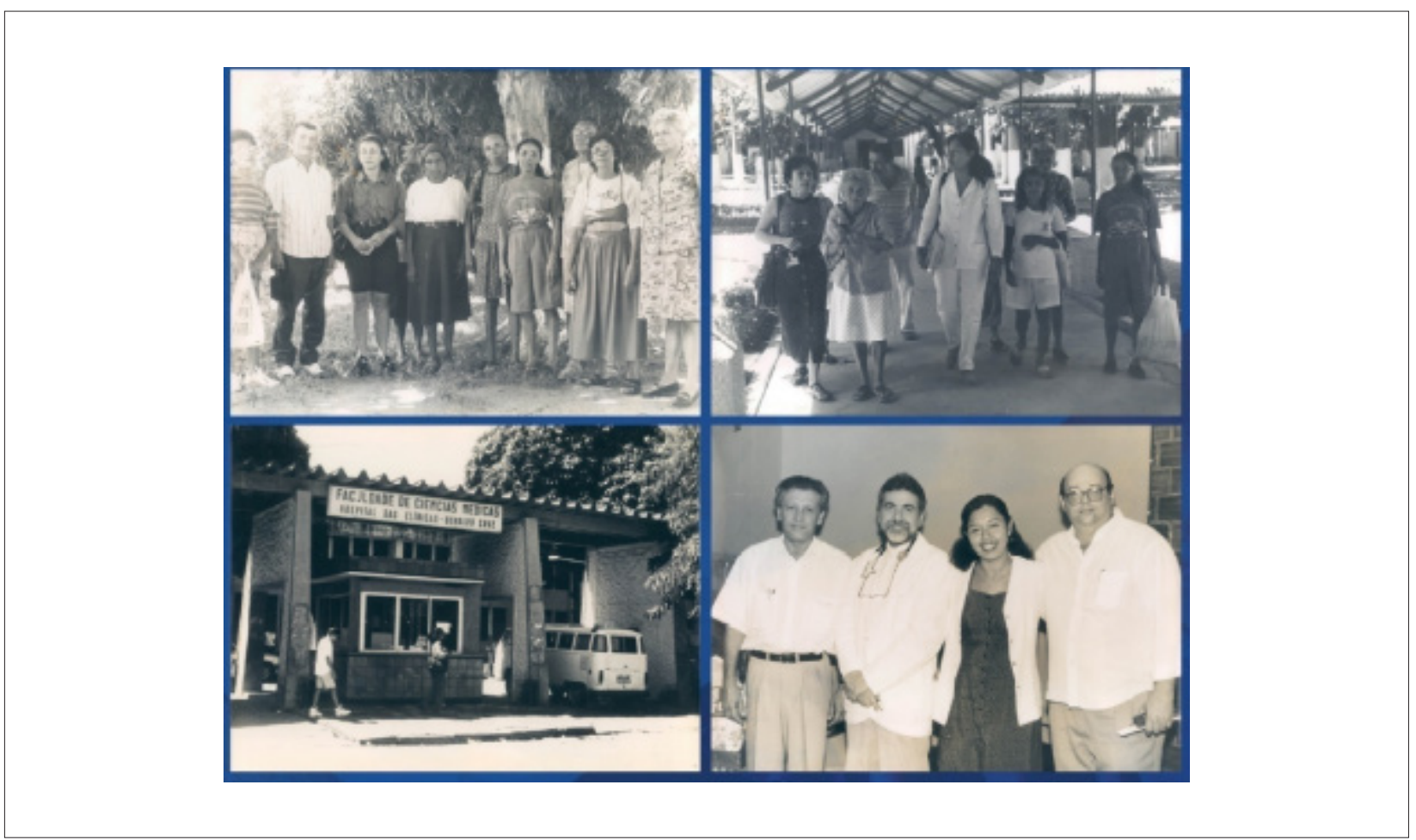

Figure 2 - First years of the outpatient clinic. On photo No. 4, from left to right: physicians Enio Cantarelli, Wilson de Oliveira Jr., Cassandra Barros, and Ricardo Paiva.

As years went by, the outpatient clinic gained capillarity and included the pharmacological and non-pharmacological treatment of Chagas disease, chagasic and non-chagasic heart failure, and the evaluation and follow-up of patients with pacemakers (PMs) and implantable cardioverter-defibrillators (ICDs). As the work expanded and became known beyond the walls of HUOC, the Chagas Disease Outpatient Clinic was sought by the board of directors of the Pernambuco
Hematology and Hemotherapy Center (Hemope), who aimed to refer blood donors with positive Chagas disease serology tests for diagnostic characterization and the follow-up of confirmed patients.

At the beginning of the 21st century, the activities performed by the clinic and the association had spread far beyond the state of Pernambuco. The result obtained through the adoption of the whole health model of care, 
which also involved the association of patients and family members, surpassed territorial boundaries. In 2007, the physician Wilson de Oliveira Jr. answered an invitation by the $\mathrm{WHO}$ and represented the service, which he coordinated, in presenting the successful experience performed in the state of Pernambuco; it later became a model and inspiration for other organizations and associations worldwide.

In 2006, with the inauguration of the Prof. Luiz Tavares Cardiology Emergency Unit of Pernambuco, at Universidade de Pernambuco - Procape, envisioned and founded by Professor Enio Lustosa Cantarelli, (Figure 3) in addition to an increase in the number of patients (especially those with PMs and ICDs), a physical space was needed to accommodate the activities of the Chagas Disease and Heart Failure Outpatient Clinic, as well as the Pernambuco Association of Chagas Disease Patients' headquarters.

By the end of 2009, owing to the Chagas Disease Outpatient Clinic coordinator and his team, the Procape director, and association volunteers, a fundraising campaign was launched, receiving donations both from individuals and private institutions, with the aim of instituting House for Patients with Chagas Disease and Heart Failure of Pernambuco (Casa do Portador de Doença de Chagas e Insuficiência Cardíaca de Pernambuco)/Procape-UPE. The project was supported by Professor João Regis and the university dean Carlos Calado. A building that could accommodate the clinic and the association headquarters was purchased, and it was inaugurated in December 2010.

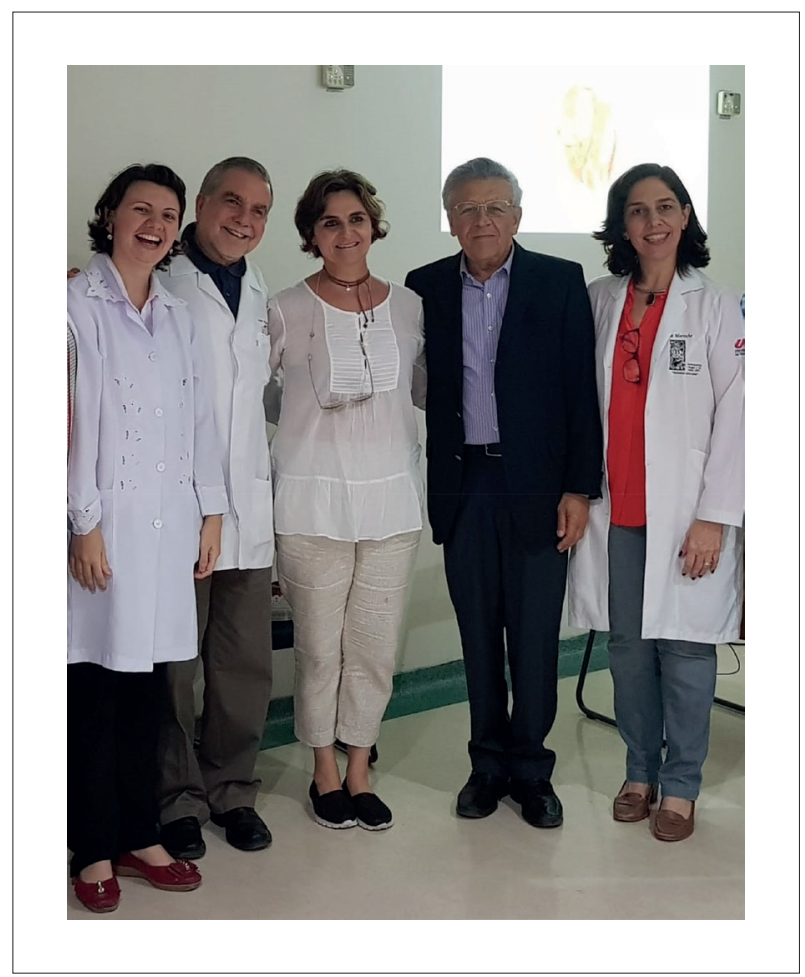

Figure 3 - Visit of Professor Enio Cantarelli. Carolina Medeiros, Wilson Oliveira Jr, Maria das Neves Dantas, and Silvia Marinho Martins.
Over time, the "Casa de Chagas" (Figure 4) house allowed a better welcome and care of these patients. The service has four specialized consultation rooms, is suited to patients with special needs, completely computerized, and connected to Procape via electronic medical records; it also offers a space for welcoming and socializing, equipped with audio and video resources, where special projects are conducted (Figure 5).

\section{A neglected disease}

Chagas disease is among the 21 diseases considered as neglected by $\mathrm{WHO} / 2021$. These are diseases that could be treated and cured in most cases, but that unfortunately affect entirely neglected populations. As opposed to global diseases such as arterial hypertension and diabetes, despite the progress of science, neglected diseases do not raise interest by the pharmaceutical industry and continue being diagnosed and treated as they were years ago, without significant advancements due to the lack of research funding. In addition to Chagas disease, the neglected diseases list includes schistosomiasis, malaria, Hansen's disease, and other conditions. These diseases end up resulting in significant stigma for the patient. Therefore, it is fundamental to understand that the patient with Chagas disease, just as the condition, is also neglected. His or her life conditions determine the onset of the disease.

The WHO estimates that between 6 and 7 million people are contaminated by Chagas disease worldwide, living precariously in endemic and non-endemic countries and with limited power for revindication. Nowadays, Chagas disease is predominantly urban, since more than two-thirds of the infected individuals live in cities, and the high proportion of undiagnosed cases represents a great challenge. It is estimated that less than $10 \%$ of people with Chagas disease worldwide are adequately diagnosed and treated. ${ }^{3}$

Even 112 years after the discovery of the now considered "the most Brazilian of diseases" by Carlos Chagas, this condition continues to represent a severe global public health problem. At the moment of the discovery, with its acute social conscience, the physician described its clinical manifestations and natural reservoirs, in addition to the profile of affected persons, thus establishing a cause-effect relationship between low socioeconomic classes and the presence of the disease.

The infection was originally restricted to rural areas. With the human presence in this environment, Chagas disease began affecting man and became a zoonosis. With the strong rural exodus occurred in the 20th century, patients with Chagas disease brought the disease to the city. It is estimated that currently, in Brazil, 70\% of the patients with Chagas disease live in the outskirts of large cities in endemic Latin American countries, shaping a true urban endemic. ${ }^{4}$ In the 1990s/2000s, due to the increase in migration between continents, Chagas disease was considered globalized, with affected persons throughout the globe.

These social aspects were fundamental for guiding the clinic's actions. Biopsychosocial demands transcended the uniquely biomedical health care. At first, most patients who arrived at the HUOC ward came from the countryside and were young adults with severe visceral impairment, mainly 


\section{Special Article}

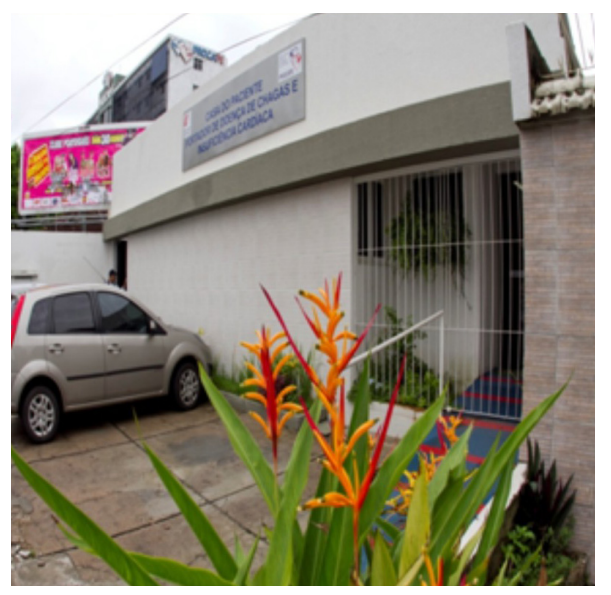

Figure 4 - Casa de Chagas house front.

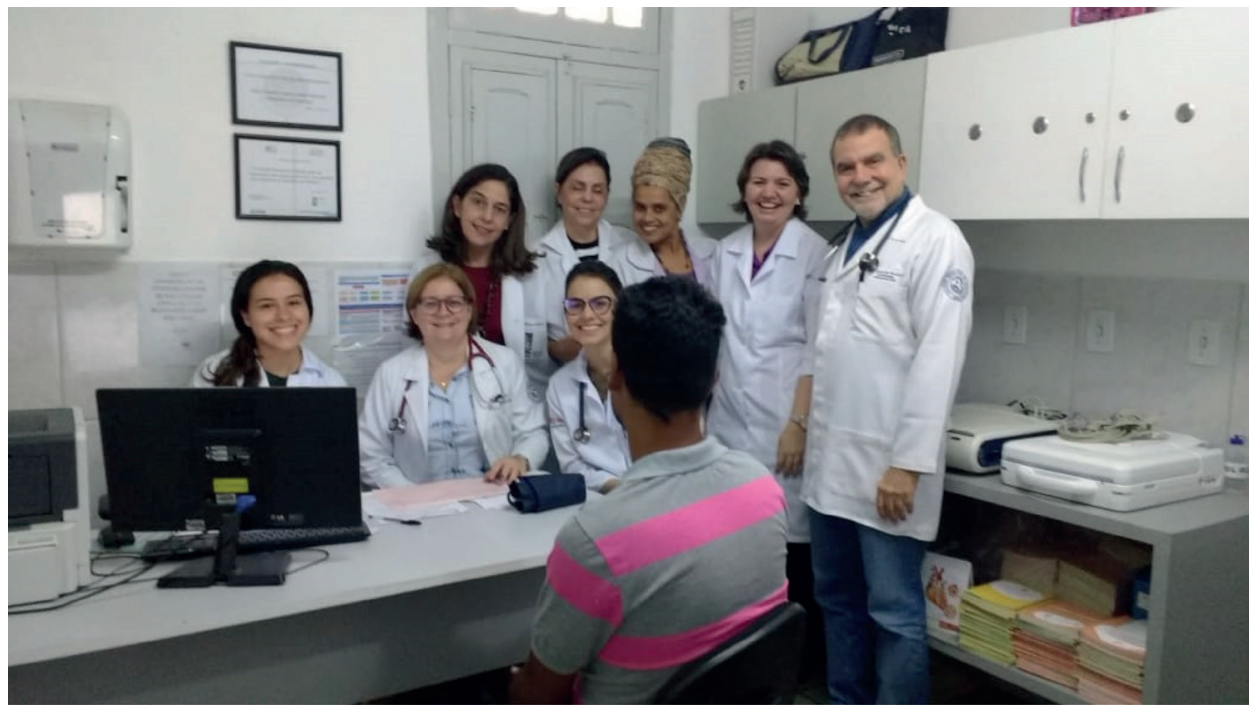

Figure 5 - Part of the team in one of the consultation rooms of the house.

of cardiac nature. A family history of sudden death was frequently reported, with prematurely lost lives, having a strong psychological impact with the fear of the imminent possibility of death. After improvements in the clinic's infrastructure with a space dedicated to these patients, the team began an active search between family members aiming to perform the early diagnosis of new cases, especially among asymptomatic patients exposed to the same contamination risk.

As years went by, this patient profile gained new nuances. In the early 1990s, with the appearance and spread of HIV, blood centers were required to perform a series of tests for releasing blood donations. The serology test for Chagas disease was among the tests that were previously only recommended and became mandatory. Therefore, these ex-blood donors, now patients of the clinic, shaped a new profile of people affected by Chagas disease. These "new" patients were young, predominantly male, asymptomatic, and born and living in urban areas. Many of them did not know the forms of transmission of Chagas disease and had epidemiological clinical data that differed from those of the group of patients previously treated by the ward. These young patients were frequently anxious when arriving at the clinic, with many doubts and taboos regarding the disease. 
The successful partnership between the clinic and blood centers guaranteed adequate care to many patients and enabled the registration and comprehension of the size of the disease presence in the state of Pernambuco. It also promoted improvements in the physical structure of the clinic and the incorporation of new professionals for acting on health care, research, and education regarding the disease.

In this scenario, in May 2011 the Health Secretary of Pernambuco (SES) created the Program to Combat Neglected Diseases/Sanar, aiming to "reduce or eliminate transmissible neglected diseases". ${ }^{5}$ The creation of the Sanar program was recognized as a successful action in Brazil and was an important turning point in the planning and actions for addressing Chagas disease in Pernambuco. This initiative positively impacted the actions of the Chagas Disease and Heart Failure Outpatient Clinic/Procape-UPE, establishing it as a State Referral Outpatient Clinic for Chagas Disease and Heart Failure; this way, partnerships for decentralization, training, professional allocation, education, and associative actions were developed. The partnership between the Referral Clinic and Sanar joined forces for creating strategies that would help fighting this disease.

Perhaps the action deserving the most attention is the decentralization program for the care of patients with Chagas disease, which is still active. Since 2012, a group formed by members of the clinic and Sanar teams have visited health care management units (GERES-Gerências regionais de Saúde) throughout the state in order to prepare health teams of these regions to receive and care for patients with Chagas disease. Formative work was performed with these professionals so that the patient could receive care at his or her region without having to be transferred to Recife. Moreover, an interconnected human serological diagnostic network was created, and the state pharmacy network was trained for the regional distribution of continuous-use medications and Benznidazole for the etiological treatment of Chagas disease, when recommended.

This action aims to provide care for patients with a positive serological test but no clinical manifestations and those with mild symptoms who can be treated at primary health care services, performing health care exactly as done by the SUS. This way, the clinic would receive a profile of patients with more severe heart failure or those in need of a PM and/or ICD. The proposal also includes telemedicine and a communication channel between the end point physician and specialists at Casa de Chagas (Figure 6).

\section{Profile of patients cared for by the State Referral Outpatient Clinic for Chagas Disease and Heart Failure}

Unfortunately, many years after the discovery of this disease, the sociodemographic profile of patients cared for by the clinic remains very similar to that described by Carlos Chagas, except for the older age. In the last statistical analysis performed by the clinic team, out of 880 patients, $69 \%$ were women, the mean age was 62 years, $38 \%$ were born at the Pernambuco Zona da Mata region, while $17 \%$ were born in the Sertão region, 24\% were from the Agreste region, 5\% were

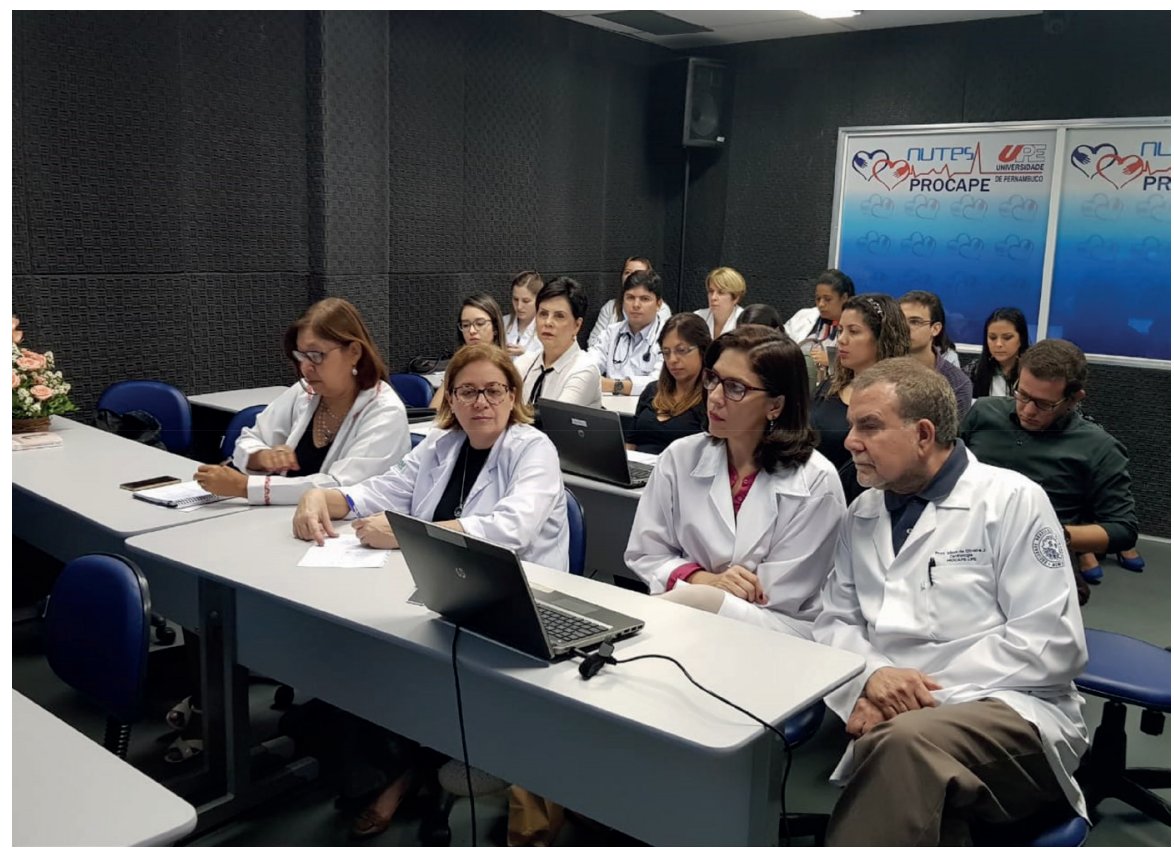

Figure 6 - Meeting with the inland management teams, in partnership with Sanar and the Telessaúde Center (Nutes). 


\section{Special Article}

from the outskirts of Recife, and 16\% were born in other states. Regarding their place of residence, $45 \%$ lived in the outskirts of Recife, although most of them were from endemic areas in the countryside. More than half of the patients were of mixed race and $69 \%$ of them did not finish primary school; $82 \%$ had an income of a minimum wage or less and $35 \%$ were rural workers. In this demographic, the clinical classification of the disease was presented as follows: $21 \%$ as A, $46 \%$ as B1, $7 \%$ as $B 2$, and $26 \%$ as C (various degrees of heart failure), classified according to the I Latin American Guideline for Chagas Disease, 2011. ${ }^{6}$ Among the most frequent comorbidities in this group, we cite systemic arterial hypertension (73\%), Diabetes Mellitus (17\%), and coronary artery disease (8.5\%). This profile is similar to that described by other Brazilian studies when considering the mean age and socioeconomic and cultural characteristics of patients. ${ }^{6}$

Currently, services that care for patients with Chagas disease, considering the ageing of this population, should be alert for the appearance of comorbidities that are more prevalent in this age group, as demonstrated by the presented data. The presence of a cardioembolic ischemic stroke in patients with Chagas disease negatively impacts their progression. The development of brain ischemia is one of the most severe complications. Many causes have been related to the development of strokes in patients with Chagas disease with cardiac involvement. ${ }^{7}$ A recently studied sample of patients with chronic Chagas cardiomyopathy, followed-up on an outpatient basis, presented ischemic stroke in $10 \%$ of the cases, probably due to a cardioembolic mechanism.

The profile of patients with heart failure of all etiologies has some peculiarities. Most of them are from the outskirts of Recife (69\%), male (61\%), and have a higher schooling level (48.7\% with primary education) and income (35\% earn more than a minimum wage). This goes to show that, although patients with heart failure have an overt clinical syndrome, they live in a socioeconomic situation (schooling, income...) that is far from ideal, but still better than that of patients with Chagas disease.
A different experience was reported in May 2019, with the first combat of acute Chagas disease cases in the state of Pernambuco. The outbreak probably happened due to oral contamination (clinical and epidemiological data), affecting 77 people with 27 laboratory-confirmed cases within a religious mission in the city of Ibimirim, in the Sertão region of the state. All patients with laboratory confirmation were treated with Benznidazole for 60 days. There were no deaths, although 6 patients had more severe manifestations of the acute disease and required hospitalization.

\section{The need for whole health care}

Considering the complexity of Chagas disease, from the beginning the clinic proposed to offer a whole health care that would consider its previously mentioned peculiarities. Nowadays, it is known that a multi-professional team is the best alternative for providing health care to patients with chronic diseases. ${ }^{8}$ The multidisciplinary team of the Chagas Disease Outpatient Clinic includes physicians, nurses, nursing technicians, an occupational therapist, and a psychologist. Each of these members has a defined role and is aware of his or her limitations, possibilities, and responsibilities, in a process of continuous exchange and dialogue.

The family is fundamental as a part of the treatment (Figure 7). It is the third vertex of the so-called therapeutic triangle (physician, patient, and family) and has an active role in the whole process. It is essential for the patient's adhesion to medication-based (or not) treatment. Therefore, the whole health approach promotes close contact with the family, which receives the same guidance as patients, in addition to psychological support. The presence of a family member during consultations and meetings helps professionals comprehend the patient's life context and thus better direct their care. The education offered to the patient and family members begins with the assessment of their knowledge on the disease and its treatment. Through periodic educational actions, the

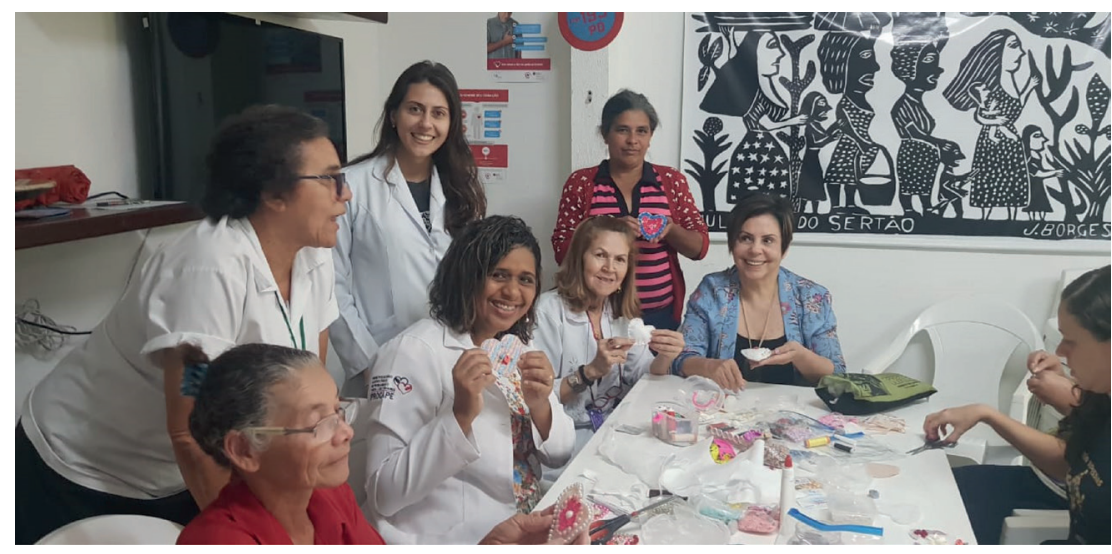

Figure 7 - Activities promoted by occupational therapy. 
multi-professional team may clarify aspects of the disease progression and treatment.

In addition to the clinic's multi-disciplinary team, focused on the patients and their families' health care and education, it is important to highlight the role of teaching and research, since this is a part of a university hospital training health professionals. The clinic thus receives medical students and residents who have the opportunity to experience and learn with the implemented practices. The outpatient clinic has, each year, expanded its academic profile, considering that multi-professional work is the ideal scenario for exchanging knowledge and practicing teamwork (Figure 8).

Throughout the years, the service has raised interest in the development of research by undergraduate (scientific initiation) and graduate (masters and $\mathrm{PhD}$ ) students, in various areas of knowledge. In addition to biomedical research, other areas connected to the humanities such as philosophy have been the object of research. Partnerships with universities and research institutes (such as FIOCRUZ) have progressively contributed to scientific production.
A group of academics participates in various activities at the clinic — the Science for Life Project (Projeto Ciência para a Vida) - , being involved in care and research activities. They feel motivated, thus collaborating with the multi-disciplinary team in periodic scientific initiation meetings (education and self-care) and performing musical presentations (Figure 9). They also participate in continued (Figure 10) education programs and conferences in the area, being more and more involved in the best possible care of patients with Chagas disease and heart failure (Figure 11).

Last but not least, volunteers have performed excellent work along with the multi-professional team and patients for the last 24 years. Most of them are also patients who, through associative actions, are empowered and become knowledgeable in the intricacies of the disease and are available for helping new patients. In reality, the attention of volunteers is aimed at the subjective and affective characteristics of patients. They welcome patients, help with educational actions on Chagas disease and general health promotion, and organize workshops and events that may help fund the association's activities (Figure 12).
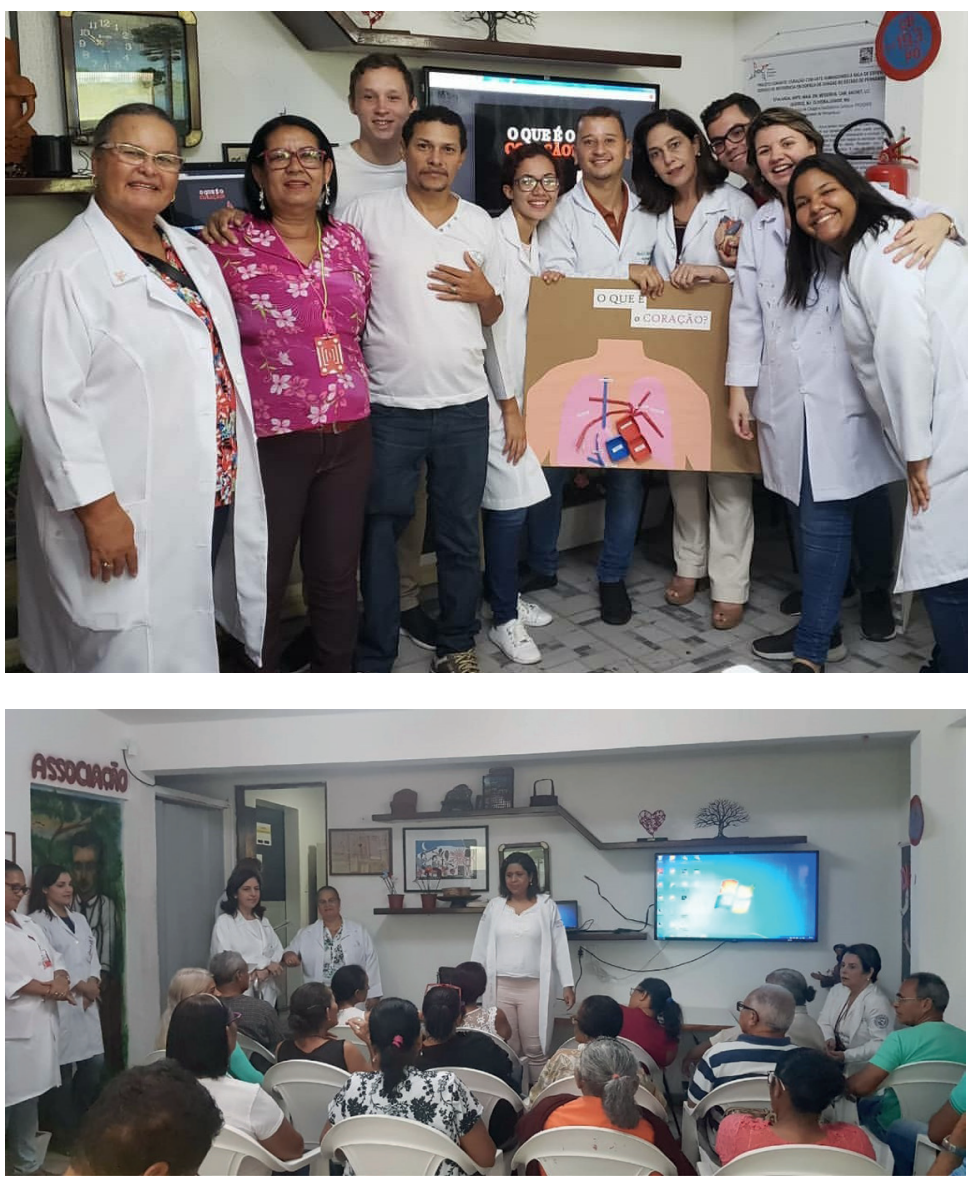

Figure 8 - Educational meetings for patients and family members with multidisciplinary team. 


\section{Special Article}
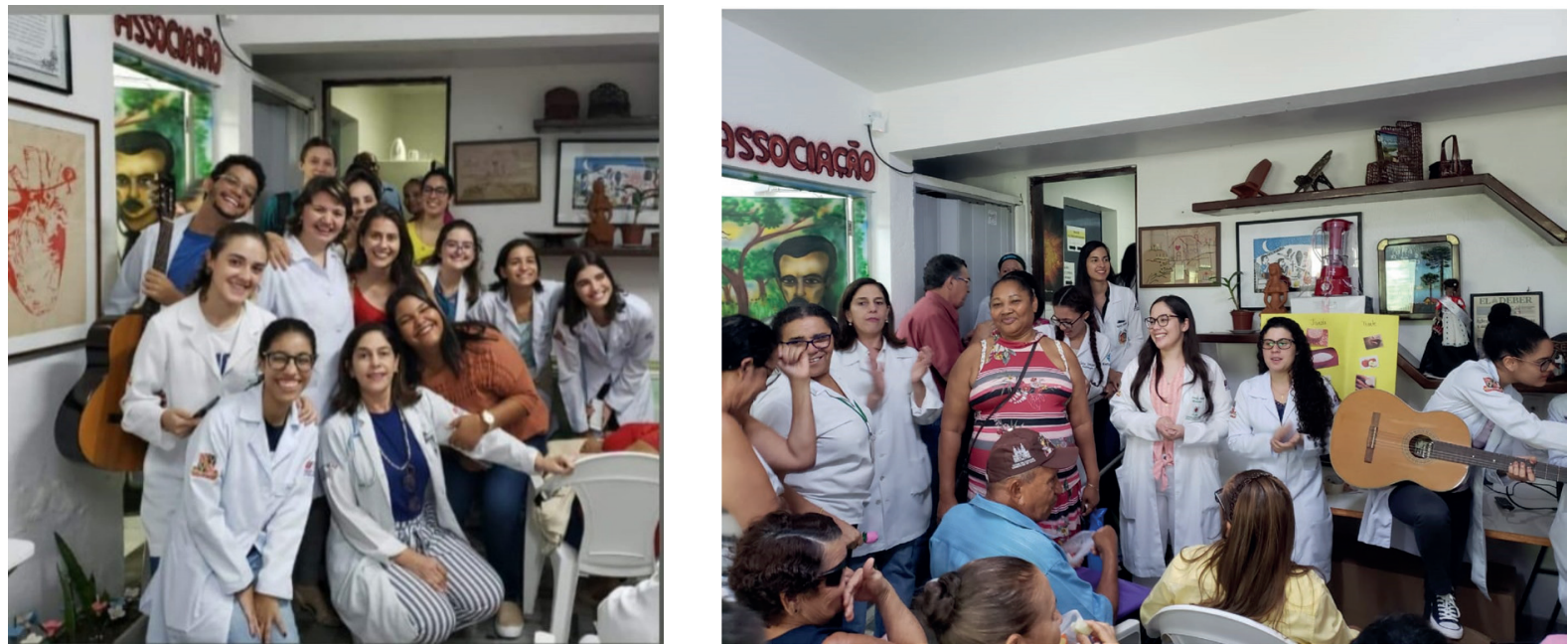

Figure 9 - The Science for Life Project (Projeto Ciência para a Vida).

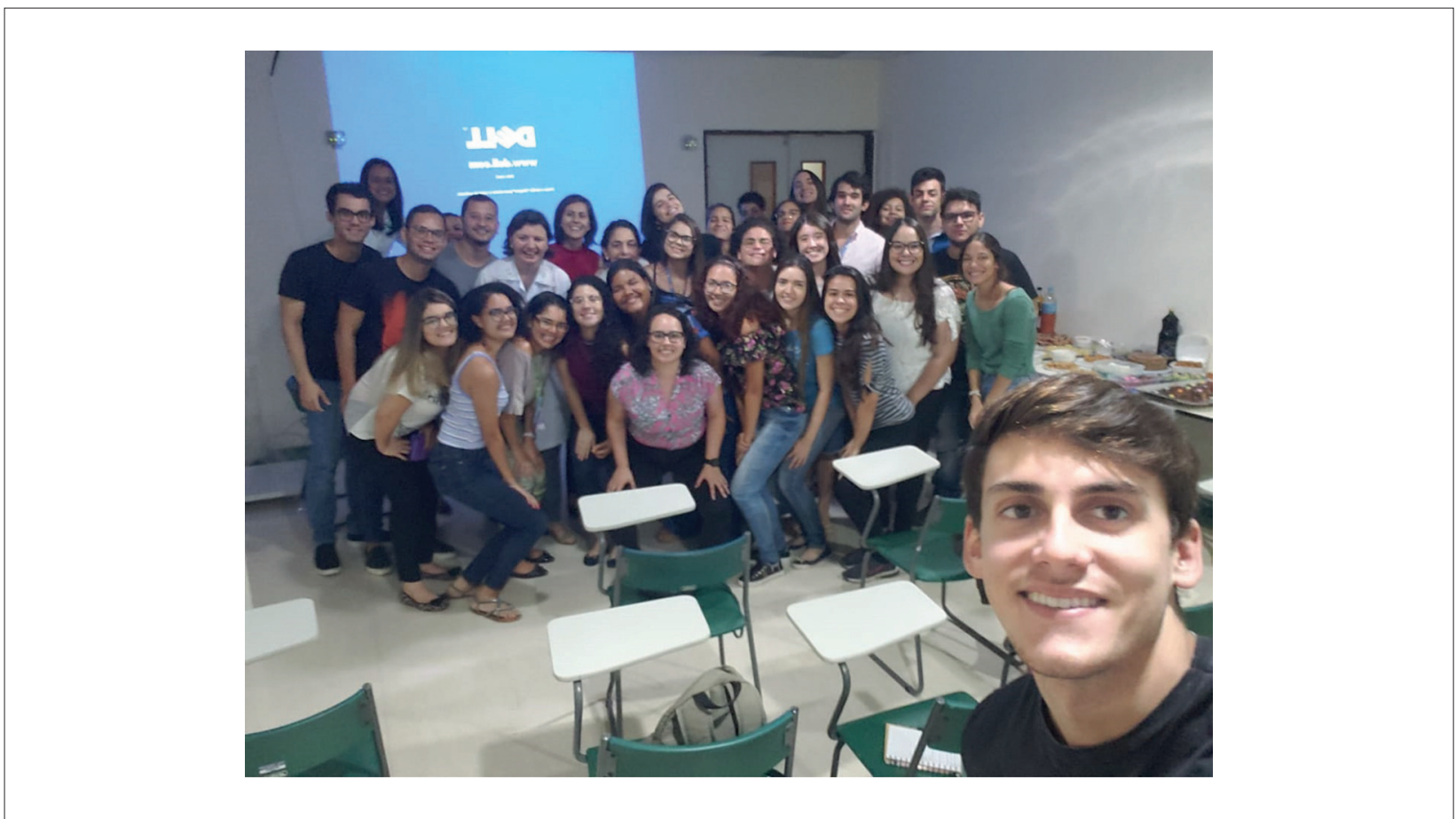

Figure 10 - Students during teaching activities.

\section{The strength of associativism}

As already mentioned, Chagas disease is neglected and strongly marked by a social bias. This characteristic renders the union and associativism of patients a natural path for them to collectively make sure they are heard. Patient associations are bio-social groups of volunteers based on common biological issues with several goals, from the guidance of patients and family members regarding treatment and quality of life to an active participation in the elaboration and implementation of public healthpolicies. ${ }^{9}$

In the case of neglected diseases, these groups are even more important. In Brazil, we highlight the Movement for the Reintegration of Persons Affected by Hansen's disease (Movimento de Reintegração das Pessoas com Hanseníase, 


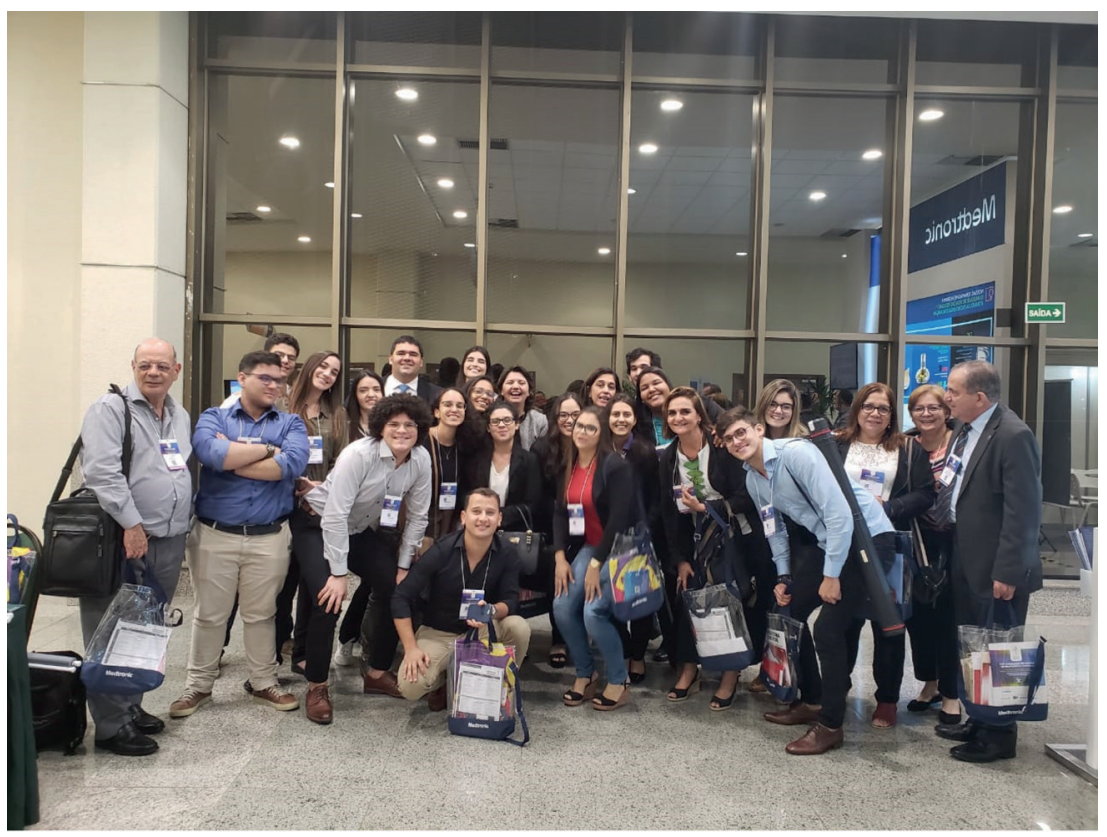

Figure 11 Participation of the outpatient clinic team and students at DEIC 2019, Fortaleza.
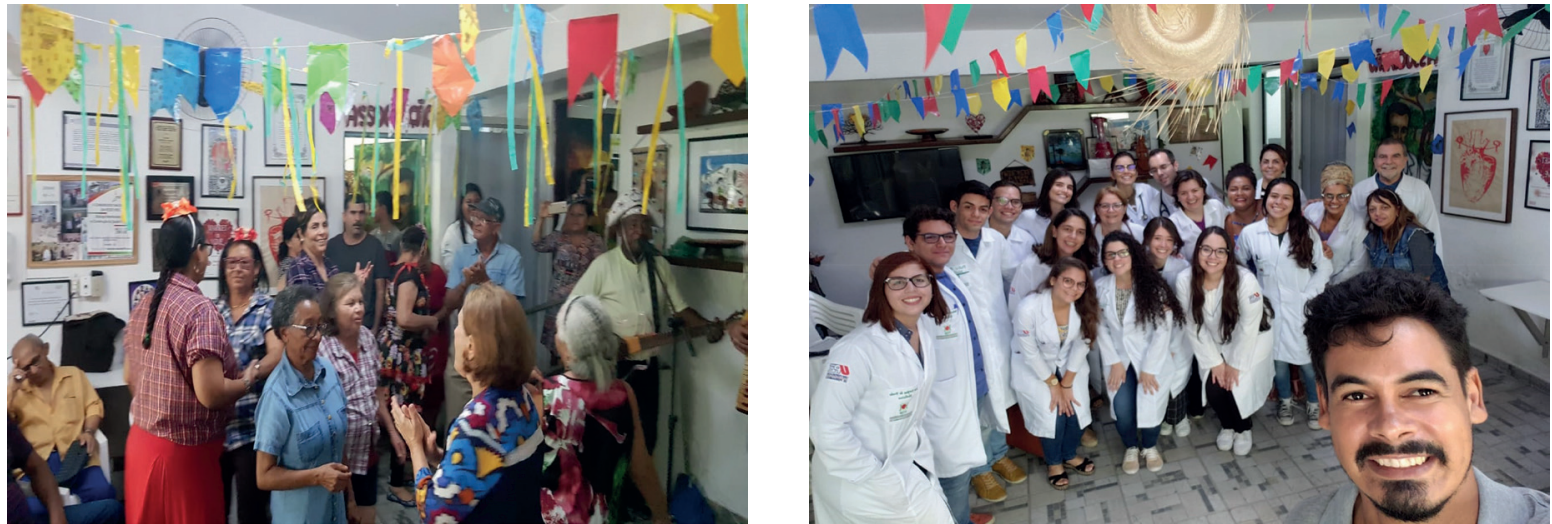

Figure 12 - On holidays, volunteers and the team promoted actions for the patients.pacientes.

Morhan), founded in 1940. Regarding Chagas disease, the worldwide pioneer was the group created in the state of Pernambuco, in 1987, along with the team of the Chagas Disease Outpatient Clinic at HUOC. The aim of this initiative was to mainly tend to the psychosocial demands of patients affected by this disease, which transcended purely biomedical aspects. The Pernambuco association is a nonprofit organization with no political affiliation, whose board of directors is formed by patients who are elected by general assembly, respecting determinations by the Brazilian Civil
Code. The association currently has 740 active members living in the outskirts of Recife and inland regions. This collective action overcame challenges, conquered spaces, empowered patients, and helped them emerge from invisibility.

In 2005, the WHO Program for the Control of Neglected Tropical Diseases classified Chagas as an extremely neglected disease, corroborating the need for the affected population to form associative groups. In this context, APDCIM (Associação dos portadores de Doença de Chagas, Insufiência Cardíaca e Miocardiopatia de Pernambuco) 


\section{Special Article}

became an important reference worldwide due to its effectivity and pioneer nature, influencing the creation of other groups in Brazil and other countries.

Currently and with equal importance, 20 associations of persons affected by Chagas disease are distributed throughout various countries (Argentina, Australia, Bolivia, Brazil, Colombia, Spain, USA, Italy, Mexico, Switzerland, Venezuela, and Japan) and have been working in a collective biocitizenship project. This group of associations has fought for the construction of a collective identity and for the mobilization and production of knowledge, culminating in public policies .

The associations of people affected by Chagas disease thus have a fundamental role in the world to help identifying similarities, clarifying and guiding people through the disease and its development process, as well as through the need for diagnosis and treatment regardless of the person's location. In spite of their regional differences, associative movements aimed at Chagas disease, in Brazil and worldwide, have one fight and mission in common: the wellbeing of the affected person. Whether they are in endemic or non-endemic countries, these associations seek to contribute to the construction of a solid identity and to strengthen citizenship.

In April 2009, during the II Catalan Journey of International Health - Tropical Medicine and the inauguration of the Barcelona patient association, the dream of creating a global federation that could unite all groups was born, as a historical milestone for the 100th anniversary of the discovery of the disease. In October of the same year, the dream began to take shape during the 25th Annual Meeting on Applied Research in Chagas Disease, in Uberaba (MG), presided by Professors José Rodrigues Coura and João Carlos Pinto Dias, where the first Meeting of Associations of Patients with Chagas Disease of the Americas, Europe, and Western Pacific took place. This meeting approached the creation of a World Federation that would be capable of welcoming and strengthening current associations and stimulating the creation of new social movements, especially in regions where the person affected by Chagas disease was in a situation of increased vulnerability. Finally, the seed of the future federation was planted, being properly founded in Pernambuco in 2010 and named International Federation of Associations of People Affected by Chagas Disease/FINDECHAGAS (Figure 13).

Many meetings and assemblies followed, uniting patients from throughout the world. The exchange of information and experiences is extremely fruitful, has brought concrete impacts to the quality of life of patients with Chagas disease, and has propagated their voice more strongly. Among the many achievements of FINDECHAGAS, we highlight the recognition of April 14 as the World Chagas Disease Day by WHO. This date was chosen because on this day, in 1909, the researcher Carlos Chagas presented his discovery to the scientific community (Figure 14).

Undoubtedly, considering all difficulties and barriers faced by patient associations, they have gained increasing importance by organizing collectively and by federation in the last decades. This joint action promotes a change in paradigm

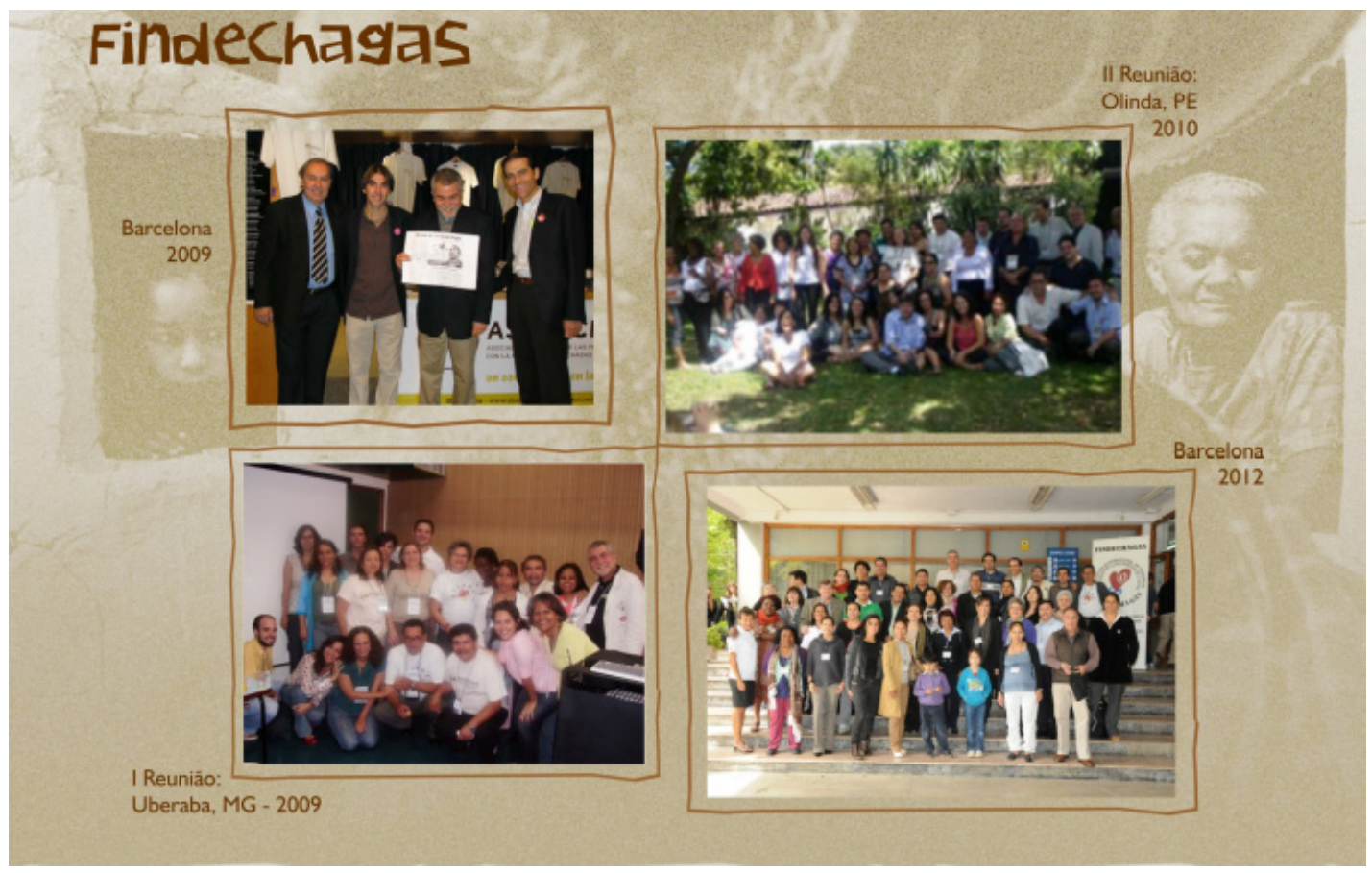

Figure 13 - (1) ASAPECHA Inauguration, Barcelona (2) First international reunion of Associations of Patients with Chagas Disease/Uberaba-MG (3) Creation of FINDECHAGAS/Olinda-PE (4) II FINDECHAGAS Assembly/Barcelona. 


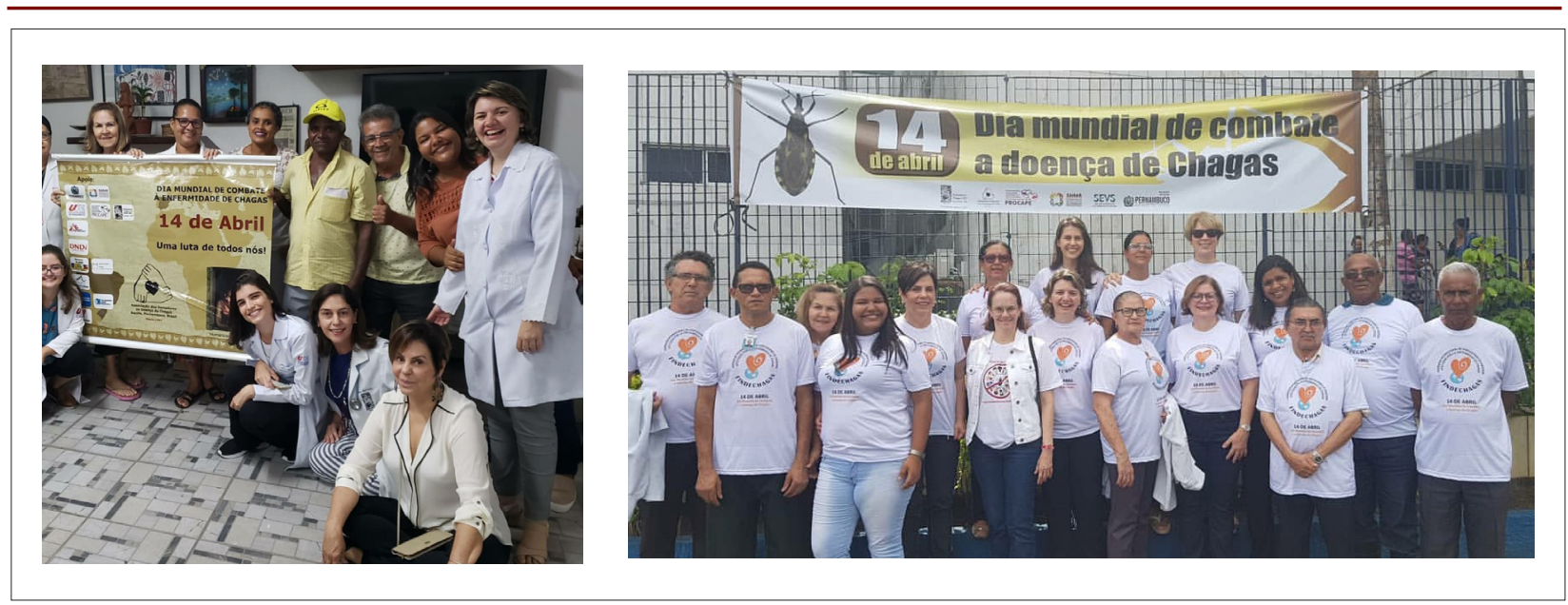

Figure 14 - Activities promoted on April 14.

where the patient moves from a passive role in his or her therapeutic process to an active position, performing patient advocacy. This proactive posture, with critical conscience of their rights and needs, favors decision making towards the best options for their health and that of the group. These groups work as a link between the State and society, thus exerting social control.

\section{Final considerations}

Today, in 2021, the history of the Chagas Disease and Heart Failure Outpatient Clinic and the Association of Chagas Disease and Heart Failure Patients follows its path and faces new challenges. As of last year, the new coronavirus pandemic directly impacted the manner of organizing and acting. The clinic had to adapt to sanitary measures so that it could continue providing care, teaching, and research, remaining alert to patients that were strongly impacted by new dynamics imposed by the pandemic. APDCIM has worked to secure funding for food items, personal and home hygiene kits, masks, medications, etc. destined to patients in need, in addition to fighting for COVID-19 vaccination priority for this group.

Throughout more than 30 years of activities, the clinic and the association have made a difference in the treatment and welcoming of patients with Chagas disease and heart failure. Their successful activity became an inspiration for many other services that today, together, can echo the voice of these patients. The perspective remains the same: to look beyond the disease and see the person in his or her whole context, welcoming, listening, and caring. The motto remains the same, today and always, "A commitment with life." All of this was only possible thanks to the cohesion of the team that faced and still faces barriers and difficulties for implementing their mission: "Humanizing for Caring."

\section{Author Contributions}

Conception and design of the research: Martins SM, Carrazzone CFV, Oliveira Junior W; Acquisition of data: Martins SM, Carrazzone CFV, Medeiros CA, Oliveira Junior W; Analysis and interpretation of the data: Martins SM, Moura CBC, Cavalcanti MGAM, Carrazzone CFV, Medeiros CA, Oliveira Junior W; Writing of the manuscript: Martins SM, Carrazzone CFV, Medeiros CA, Oliveira Junior W; Critical revision of the manuscript for intellectual content: Martins SM, Moura CBC, Cavalcanti MGAM, Carrazzone CFV, Oliveira Junior W.

\section{Ethics approval and consent to participate}

This article does not contain any studies with human participants or animals performed by any of the authors.

\section{Potential Conflict of Interest}

No potential conflict of interest relevant to this article was reported.

\section{Sources of Funding}

There were no external funding sources for this study.

\section{Study Association}

This study is not associated with any thesis or dissertation work. 


\section{Special Article}

\section{References}

1. Jan CJ, Chang CJ, Hwang SJ, Chen TJ, Yang HY, Chen YC, et al. Impact of team-based community healthcare on preventable hospitalisation: a population-based cohort study in Taiwan. BMJ Open. 2021;11(2):e039986. doi: 10.1136/bmjopen-2020-039986.

2. McAlister FA, Stewart S, Ferrua S, McMurray JJ. Multidisciplinary strategies for the management of heart failure patients at high risk for admission: a systematic review of randomized trials. J Am Coll Cardiol. 2004;44(4):810-9. doi: 10.1016/j.jacc.2004.05.055.

3. Médicos Sem Fronteiras (Brasil). Mobilização popular e doença de chagas: guia para o fortalecimento e a formação de associações de pessoas afetadas pela doença de chagas. Rio de Janeiro: Médicos Sem Fronteiras; 2015.

4. Silva EF, Oliveira AL, SieferMW, Gazetta ML, Bertani IF. Demographic profile and worksituation of patients with Chagas disease. Arq Bras Cardiol. 1995;65(1):43-6.

5. Pernambuco. Secretaria Estadual de Saúde. Programa Sanar: doenças negligenciadas [Internet]. Recife: Secretaria Estadual de Saúde; 2021 [cited 2021 Jun 02]. Available from: http://portal.saude.pe.gov.br/ programa/secretaria-executiva-de-vigilancia-em-saude/programa-sanardoencas-negligenciadas

6. Gasparim AZ, Fontes CER, Rossoni DF, Toledo MJO. Epidemiological and clinical profile of patients with Chagas disease in the Central-North area of Paraná, Southern Brazil. Rev Soc Bras Med Trop. 2018;51(2):225-30. doi: 10.1590/0037-8682-0173-2017.

7. Carod-Artal FJ, Gascon J. Chagas disease and stroke. Lancet Neurol. 2010;9(5):533-42. doi: 10.1016/S1474-4422(10)70042-9.

8. Oliveira W Jr. All-around care for patients with Chagas disease: a challenge for the XXI century. Mem Inst Oswaldo Cruz. 2009;104 Suppl 1:181-6. doi: 10.1590/s0074-02762009000900024.

9. Amaro F, Pinto C, Carvalho MI. Associações de doentes em Portugal: problemas, necessidades e aspirações. Lisboa: Companhia das Ideias; 2015. 